\title{
The Role Played by Salicylic Acid and Omega 3 in the Placental Vascular Resistance Mechanism: A Pilot Study
}

Alice Campos Batista ${ }^{1}$, Bárbara Caetano Ribeiro ${ }^{1}$, Bia Drummond Paiva ${ }^{1}$, Laís Mapa de Brito Fernandes ${ }^{1}$, Luiza Cotta Xavier ${ }^{1}$, Maria Paula Ferreira Arcuri ${ }^{1}$, Clarissa Rocha Panconi ${ }^{2,4}$, Alexander Cangussu Silva ${ }^{2,4}$, Mariana Pinto Sirimarco ${ }^{2,4}$, Larissa Milani Coutinho ${ }^{2,4}$, Patrícia de Oliveira Lima ${ }^{3,4}$, Gabriel Duque Pannain $^{2,4}$, Iasmin Dantas Sakr Khouri ${ }^{2,4}$, Paula Silveira Mendes ${ }^{2,4}$, Miralva Aurora Galvão Carvalho ${ }^{2,4}$, Paulo Henrique Barros Valente ${ }^{2,4}$, Marcus Gomes Bastos ${ }^{2}$, Juliana Barroso Zimmermmann ${ }^{1,2,4^{*}}$

${ }^{1}$ José Bonifácio Lafayette de Andrada Foundation (FUNJOBE), Medical School of Barbacena, Barbacena, Brazil; ${ }^{2}$ Federal University of Juiz de Fora (UFJF), Juiz de Fora, Brazil; ${ }^{3}$ University Hospital (UFJF), EBSERH, Santa Catarina, Juiz de Fora, Brazil; ${ }^{4}$ High Risk Prenatal Care Group, Brazil

\begin{abstract}
Introduction: Doppler flowmetry of uterine arteries allows identifying women at risk of developing preeclampsia (PE), mainly early preeclampsia; it also facilitates the timely use of prophylaxis. Minidose Acetylsalicylic Acid (ASA) can help preventing/delaying preeclampsia development, as well as reducing its severity and the risk of complications. However, not all patients can use this medication; therefore, it is necessary finding clinical alternatives for pregnant women who do not tolerate ASA, as well as evaluating the possibility of increasing this prophylaxis with new drugsthe use of omega 3 is one of these alternatives. Thus, it is possible assuming that omega use by pregnant women could reduce the vascular resistance of uterine arteries and facilitate placentation. The aim of the current study is to evaluate uterine artery resistance and pulsatility indices, as well as bilateral notch in pregnant women presenting identifiable risk factor for PE development, who use omega 3 in association, or not, with ASA.

Methodology: The current research is a randomized-controlled, non-blind, parallel, two-arm, open-label preventive clinical trial. Patients were divided into two groups: group 1-use of ASA; and group 2-use of ASA+omega 3. Omegabased supplementations comprised doses of $400 \mathrm{mg} /$ day in gelatin capsules, at DHA: EPA ratios 2.5:1 and 5.0:1.

Results: Patients' mean age was $33.48+4.68$ years. Mean pregnancies and childbirths were $1.93+1.30$ and $0.59 \pm 0.37$, respectively. Results of uterine artery Doppler flowmetry were associated with omega and/or ASA use; patients who used ASA in association with omega (ASA+omega) recorded the highest uterine artery resistance and pulsatility indices - results were statistically significant. The comparison between ASA use in association, or not, with omega did not show difference in PE, prematurity, oligohydramnios, IUGR or hospitalization in neonatal ICU frequency. There were no cases of fetal death or Hellp Syndrome in either groups.

Conclusion: The omega 3 use in association with ASA has increased the uterine artery resistance and pulsatility indices of the investigated patients; however, it did not make any difference in primary and secondary outcomes.

Keywords: Prenatal care; Acetyl salicylic acid; Omega
\end{abstract}

*Correspondence to: Dr. Juliana Barroso Zimmermmann, Federal University of Juiz de For a (UFJF), Juiz de Fora, Brazil, Tel: +5532988483345; Email: julianabz@uol.com.br

Received: September 13, 2019; Accepted: September 23, 2019; Published: September 30, 2019

Citation: Batista AC, Ribeiro BC, Paiva BD, Fernandes LMD, Xavier LC, Arcuri MPF, et al. (2019) The Role Played by Salicylic Acid and Omega 3 in the Placental Vascular Resistance Mechanism: A Pilot Study. Clinics Mother Child Health. 16:333. DOI: 10.35248/2090-7214.19.16.333

Copyright: (C2019 Batista AC, et al. This is an open-access article distributed under the terms of the Creative Commons Attribution License, which permits unrestricted use, distribution, and reproduction in any medium, provided the original author and source are credited. 


\section{INTRODUCTION}

Maternal inflammatory response at placentation time may be of paramount importance to help better understanding the etiopathogenesis of a series of pathologies such as hypertensive syndromes during pregnancy. Understanding this process also means understanding that the optimal placental function can be impaired by several mechanisms such as hypertension, oxidative stress, thrombophilias and, consequently, infarcts caused by changes in placental perfusion [1].

Hypertensive conditions in the third gestational trimester may be an adaptive response of pregnant women to low uteroplacental perfusion in order to maintain adequate blood flow in the fetal compartment. Myometrial segments of uteroplacental circulation suffer severe hyperplasia and arteriosclerosis, in opposition to high resistance and peripheral pressure, a fat that changes the placentation mechanism and leads to increased hypoxia, vasospasm and oxidative stress [2-4]. The repercussion of such changes can be identified in uterine artery Doppler; they are depicted by increased resistance and pulsatility indices and by bilateral protodiastolic notch, which happens due to non-trophoblastic invasion in the myometrial segment of the spiral arteries [5].

Thus, Doppler flowmetry of uterine arteries allows identifying pregnant women at risk of developing preeclampsia (PE), mainly early preeclampsia, and it facilitates the timely use of prophylaxis, either to prevent or slow the development of the severe form of the disease. Thus, abnormal uterine artery Doppler findings in the first and second gestational trimesters have been indicated as appropriate screening tests to predict PE, intrauterine growth restriction (IUGR) and placental abruption (PA) [6-8].

Minidose acetylsalicylic acid (ASA) can help preventing/delaying preeclampsia development, as well as reducing its severity and the risk of complications. Minidose ASA can selectively inhibit the cyclooxygenase pathway in platelets, but not in the vascular endothelium; it blocks thromboxane synthesis, but not prostacyclin synthesis; it prevents vasoconstriction and pathological coagulation in the placenta. According to Trivedi et al. [9], low-dose ASA helps preventing preeclampsia in high-risk pregnant women $(\mathrm{RR}=0.79 ; 95 \% \mathrm{CI} ; 0.65-0.97)$, although it has no effect on low-risk pregnant women $(\mathrm{RR}=0.86$; $95 \% \mathrm{CI}$; 0.64-1.1). These findings meet the study by Ruano et al. [10], who identified ASA protective effect against PE development in high-risk pregnant women $(\mathrm{RR}=0.87 ; 95 \% \mathrm{CI}, 0.79-0.96)$, but not in low-risk pregnant women $(\mathrm{RR}=0.95$; $95 \% \mathrm{CI}$; 0.81-1.11). According to the systematic review carried out by Henderson et al. [11], the use of low-dose ASA helps preventing preeclampsia in high-risk pregnant women ( $R R=0.76 ; 95 \% \mathrm{CI} ; 0.62-0.95)$. Another study was conducted with 1,776 pregnant women, who started taking aspirin $(150 \mathrm{mg} /$ day $)$ or placebo between the 11 th and 14th gestational weeks. Results have shown that aspirin has successfully reduced $\mathrm{PE}$ rates in comparison to the placebo $(p=0.004)$ [12]. Based on the ASPRE trial, low-dose aspirin has successfully reduced the risk of PE development before the $32 \mathrm{nd}$ gestational week and before the 37 th gestational week; however, it did not reduce the risk of PE development in pregnant women after the 37 th gestational week $[13,14]$. Thus, it is possible saying that aspirin (ASA) plays a key role in the prophylaxis of women experiencing risk pregnancies [9-13].

However, not all patients can use ASA. Patients with peptic ulcers, gastritis, Chron's disease, ulcerative colitis and ASA intolerance should not take this medication on a daily basis. In addition, aspirin does not appear to be totally harmless. Xu [15] has found increased likelihood of placental abruption in pregnant women using aspirin $(\mathrm{OR}=1.35 ; \quad \mathrm{CI}=1.05-1.73$; $\mathrm{p}=0.02)$, as well as higher frequency of bleeding episodes $(5.6$ episodes/1000 patients/year). An Italian study has found that ASA increased gastrointestinal and brain bleeding [16].

It is necessary finding clinical alternatives for pregnant women who do not tolerate ASA, as well as evaluating the likelihood of increasing this prophylaxis with new drugs. Moreover, the likelihood of reducing vascular resistance, even in ASA users, appears to be a good alternative to maintain satisfactory placental flow. The use of essential fatty acids (FA) is a new perspective that seems to be applicable in daily medical practice. These fatty acids are part of lipids (or fats) and they comprise the carboxyl group $(\mathrm{COOH})$. Their chains are aliphatic, i.e., they are open and seen as organic components because their molecules have carbon and hydrogen, which are produced when fats are disrupted. Among these fatty acids, one finds the alpha-linolenic (ALA-omega 3) and linoleic (LA-omega 6) acids, which are converted by enzymes such as elongases and desaturases. ALA converts into eicosapentaenoic (EPA) and docosahexaenoic (DHA) acids, whereas LA converts into arachidonic acid (AA) [16].

Recent studies have found that fatty acids can increase blood flow in the uterine artery and, consequently, they can improve blood supply in this vessel [17]. This process happens because both DHA and EPA act to reduce prostaglandin E2 (proinflammatory) metabolite production and to decrease thromboxane A2 concentrations, which is a potent platelet aggregator and vasoconstrictor; to reduce leukotriene B4 formation, which induces inflammations, leukocyte adherence and chemotaxis; as well as to increase thromboxane A3 concentrations, which is a weak platelet aggregator and vasoconstrictor, prostacyclin PGI3 concentrations, which is a vasodilator and platelet aggregation inhibitor; and leukotriene B5 concentrations, which is a weak inflammation-inducer and chemotactic agent [17-20]. Based on a recent study, women who used DHA during pregnancy had lower chance of developing severe preeclampsia ( $\mathrm{RR} 0.46 ; \mathrm{CI}=0.25-0.83$ ). On the other hand, ALA intake was associated with higher risk of developing severe preeclampsia ( $R R 1.71 ; 1.07-2.75)$ [21]. The truth is that although omega can, in theory, reduce the likelihood of preeclampsia development, many trials did not show this benefit. Assumingly, these differences are associated with the selected sample type, with the adopted omega dose or even with the DHA: EPA ratio in the ingested compound, as well as with the time supplementation was implemented [22]. However, studies conducted with animals have shown promising outcomes resulting from such supplementation [23].

Accordingly, it is possible assuming that DHA use by pregnant women could reduce vascular resistance in the uterine arteries and facilitate placentation. In light of the foregoing, the aim of 
the current study was to evaluate uterine artery resistance and pulsatility indices, as well as bilateral notch, in pregnant women presenting identifiable risk factor for PE development, who used omega 3 in association, or not, with ASA.

\section{PATIENTS AND METHODS}

\section{Methodology}

The current research is a randomized-controlled, non-blind, parallel, two-arm, open-label preventive clinical trial, which comprised pregnant women who were treated in the Obstetrics services at HU-UFJF and at the Medical School of Barbacena. Patients treated in these two services were included in the current study due to the possibility of having them being assessed by the same team coordinator and of using a standard prenatal chart-in compliance with FEBRASGO standards [24]. Clinical and epidemiological data (pregnancies, miscarriages, gestational age at the beginning of prenatal care, childbirths, fetal weight, and underlying pathology) were collected during anamnesis. Primary outcome comprised high uterine artery resistance and preeclampsia, whereas secondary outcome comprised fetal weight, hospitalization in neonatal ICU, fetal death, placental abruption, Hellp syndrome and fetal death.

Pregnant women at risk of developing preeclampsia were included in the study, based on criteria set by ACOG [25] and NICE [26], which were adapted for the current study. Pregnant women at risk of developing preeclampsia comprised patients with diabetes, chronic hypertension, autoimmune or kidney diseases, thrombophilias, as well as primiparous, obese patients and women older than 35 years.

Women whose mean arterial pressure was higher than, or equal, to $100 \mathrm{mmHg}$, or whose uterine artery doppler showed notch in the first gestational trimester, were also included in the study. The presence of any of these data (anamnesis, altered blood pressure or uterine artery Doppler) was considered positive for participants' inclusion in the study. Pregnant women who did not agree to participate in the study and the ones who did not accept the service protocol were excluded from the study, as shown in Figure 1.

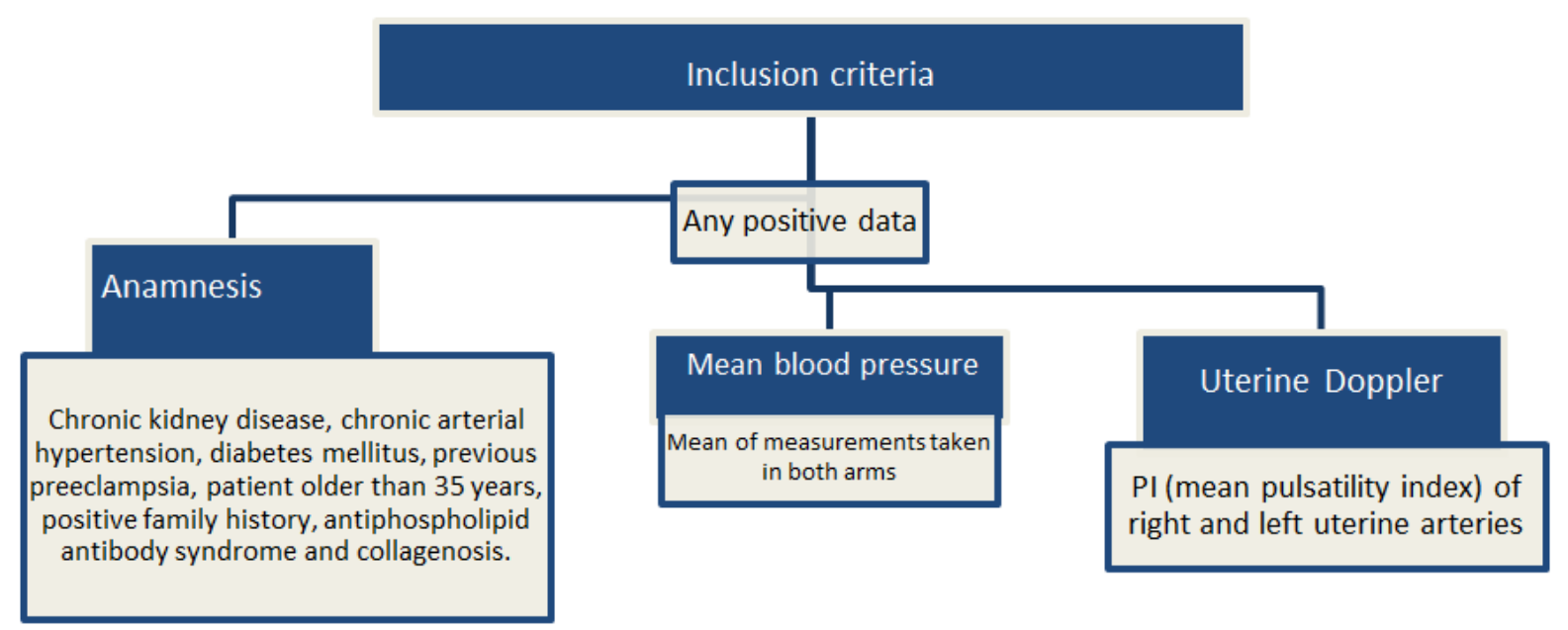

Figure 1: Inclusion criteria applied to pregnant women in the current study. Any of these positive aspects was taken as inclusion criterion in the study.

Sample calculation took into consideration the frequency of preeclampsia cases in our service-which ranged from $25 \%$ to $35 \%$ because it is a specific outpatient clinic for hypertensive diseases. The number of participants in pilot studies does not need to exceed $10 \%$ of the target sample. Based on this requirement, the minimum sample in the herein conducted pilot study comprised 40 pregnant women, who were divided into two groups: group 1- patients using ASA; and group 2 patients using ASA+omega 3. Omega supplements were taken in the gelatin capsule form (400 mg/day) at DHA: EPA ratios 2.5:1 and 5.0:1. The adopted ratio was randomly selected based on supplement availability in the obstetric service, since it was a pilot study. ASA was formulated at the dose of $100 \mathrm{mg} /$ day and patients should take it after eating, on a daily basis.

The uterine artery Doppler was carried out at the 12th gestational week and, later, between the 24th and 28th gestational weeks in order to evaluate patients' uterine arteries. Patients were placed in supine, semi-sitting position, by keeping angles of $15^{\circ}$ and $30^{\circ}$ between them and the examination table to avoid vena cava compression. Next, images were generated, and Doppler mapping was performed. The transducer was longitudinally placed in the iliac fossa, parallel to the iliac crest and to the uterine wall, in order to identify the iliac vessels. A subtle medial movement enabled seeing the uterine artery that, along with the external iliac artery, formed the false image of a cross. The uterine artery was assessed 1 to $2 \mathrm{~cm}$ away from this point, based on pulsatility index and on notch identification. Resistance (RI) and pulsatility (PI=A-B/Mean) indices were the herein adopted hemodynamic indices.

\section{Statistical analysis}

Data were digitized in electronic Access database forms specially developed for the current study. Results were expressed as mean and standard deviation (quantitative variables) and as absolute and relative frequency (categorical variables). Statistical analyses were carried out in the Statistical Package for Social Sciences 
(SPSS) software, version 13.0 for Windows (Chicago, IL, USA). Student's t-test was used to compare means between independent samples, Fischer's exact test was used, whenever possible, to assess association. The $\chi 2$ test was used to assess variables presenting more than two categories. Significance level was set at $5 \%$.

\section{Ethics}

The current study was submitted via plataforma Brasil (Brazil platform) to, and approved by, the Ethics Committee of the Medical School of Barbacena-José Bonifácio Lafayette Andrada Foundation-FAME-Barbacena. All patients signed the free and informed consent form after they were instructed as to the confidentiality of their identification data, as well as to the possibility of withdrawing at any time during the research, without any prejudice.

\section{RESULTS}

Forty-seven (47) patients treated in the aforementioned obstetrics services during this period were assessed. Patients mean age was $33.5 \pm 4.7$ years; minimum age was 23 years and maximum age was 42 years. The mean numbers of pregnancies and childbirths were $1.93 \pm 1.3$ and $0.6 \pm 0.4$, respectively. The mean number of miscarriages was $0.6 \pm 0.6$.

The analysis of previous diseases found 12 patients (26.1\%) with chronic hypertension, 1 patient (2.2\%) with kidney disease, 4 patients $(8.5 \%)$ with diabetes, and 3 patients $(6.5 \%)$ with hypothyroidism.

Uterine artery resistance and pulsatility indices are shown in Table 1; they were repeated between the 24th and 28th gestational weeks, after the screening carried out in the 12 th gestational week. The comparison between right and left uterine pulsatility indices did not show statistical difference between them $(p=0.42)$, as shown in Table 1 . The incidence of unilateral or bilateral uterine artery notch was investigated-unilateral notch was identified in $42.3 \%$ of patients, whereas bilateral notch was identified in $26.9 \%$ of them.

Table 1: Uterine artery resistance and pulsatility indices tested between the 24th and the 28th gestational week.

\begin{tabular}{lcccc}
\hline & Mean & Minimum & Maximum & Standard deviation \\
\hline Uterine artery pulsatility index in pregnant women assessed in the current study & & 0.4 \\
\hline Right Uterine Artery & 1.0 & 0.6 & 2.3 & 0.7 \\
\hline Left Uterine Artery & 0.9 & 0.3 & 3.6 & \multirow{2}{*}{. }
\end{tabular}

Uterine artery resistance index in pregnant women assessed in the current study

\begin{tabular}{llllll}
\hline Right Uterine Artery & 0.6 & 0.3 & 1.8 & 0.3 & 0.9 \\
\hline Left Uterine Artery & 0.9 & 0.3 & 3.6 & 0.9 \\
\hline
\end{tabular}

Mean Uterine Artery Index in pregnant women assessed in the current study

\begin{tabular}{llcccc}
\hline Pulsatility & 0.9 & 0.5 & 2.9 & 0.5 & 0.2 \\
\hline Resistance & 0.5 & 0.3 & 1.2 & 0.2 \\
\hline
\end{tabular}

Results of uterine artery Doppler flowmetry were associated with omega and/or ASA use, as shown in Table 2.

Table 2: Pulsatility indices in the second gestational trimester of pregnant women using AAS or AAS+omega.

\begin{tabular}{|c|c|c|c|c|c|c|}
\hline & Mean & Standard deviation & Minimum & Maximum & $\mathrm{p}$ value & $\mathrm{F}$ \\
\hline ASA & 1.0 & 0.3 & 0.6 & 1.7 & 0.01 & 7.57 \\
\hline ASA+omega & 1.9 & 1.4 & 0.9 & 2.9 & & \\
\hline
\end{tabular}

Mean uterine artery resistance index

\begin{tabular}{lllllll}
\hline ASA & 0.5 & 0.1 & 0.3 & 0.7 & 0.01 \\
\hline
\end{tabular}




\begin{tabular}{lllll}
\hline ASA+omega & 0.8 & 0.3 & 0.6 & 1.2
\end{tabular}

Patients who used ASA in association with omega (ASA+omega) recorded significantly higher resistance and pulsatility indices $(p=0.01)$. The comparison between right and left uterine arteries did not show statistically significant results $(p=0.58)$. However, the evaluation of omega concentrations (DHA/EPA ratio) in the formulation has shown that pulsatility indices recorded the lowest values when the highest DHA/EPA ratio (5:1) was adopted, as shown in Table 3, although without statistical significance. The association between notch incidence and ASA or ASA+omega use did not show statistically significant difference between treatments $(p=0.6)$.

The comparison between ASA use in association, or not, with omega did not show differences in PE $(p=0.3)$, prematurity $(p=0.9)$, oligohydramnios $\quad(p=0.1)$, IUGR $\quad(p=0.9)$ or hospitalization in neonatal ICU $(p=0.9)$ frequency. There was no case of fetal death or Hellp Syndrome in either group. Based on the neonatal weight comparison, the weight of babies born from mothers treated with omega+ASA $(3,167.5 \pm 95.5 \mathrm{~g})$ was significantly higher $(p=0.9)$ than that of babies born from mothers treated only with ASA $(3,109.0 \pm 480.9)$.

\section{DISCUSSION}

Optimal placental function can be impaired by many mechanisms such as hypertension, oxidative stress, thrombophilias and, consequently, the incidence of infarctions [1-3]. Myometrial segments of uteroplacental circulation suffer severe hyperplasia and arteriosclerosis due to high resistance and peripheral pressure, a fact that impairs placentation and leads to hypoxia, vasospasm and oxidative stress [1-5]. The uterine artery Doppler investigation allows identifying these changes based on increased resistance and pulsatility indices and on the incidence of bilateral protodiastolic notch, which happens due to nontrophoblastic invasion in the myometrial segment of the spiral arteries [1-5].

Table 3: Pulsatility and resistance indices in the second gestational trimester and their association with the DHA: EPA ratio used by pregnant women.

\section{(DHA/ EPA) Concentration Mean p value T}

Right uterine artery pulsatility index

\begin{tabular}{llll}
\hline$(2.5: 1)$ & $1.2 \pm 0.8$ & 0.35 & 0.95 \\
\cline { 1 - 1 }$(5: 1)$ & $0.85 \pm 0.4$ &
\end{tabular}

Left uterine artery pulsatility index

\begin{tabular}{llll}
\hline$(2.5: 1)$ & $1.4 \pm 1.4$ & 0.31 & 1.2 \\
\cline { 1 - 2 }$(5: 1)$ & $0.7 \pm 0.2$ & & \\
\hline
\end{tabular}

Mean uterine artery pulsatility index

\begin{tabular}{|c|c|c|c|}
\hline$(2.5: 1)$ & $1.3 \pm 1.1$ & 0.23 & 1.6 \\
\hline$(5: 1)$ & $0.7 \pm 0.09$ & & \\
\hline
\end{tabular}

Mean uterine artery resistance index

\begin{tabular}{llll}
\hline$(2.5: 1)$ & $0.5 \pm 0.2$ & 0.72 & 0.12 \\
\cline { 1 - 2 }$(5: 1)$ & $0.5 \pm 0.2$ & \\
\hline
\end{tabular}

Right uterine artery resistance index

\begin{tabular}{llll}
\hline$(2.5: 1)$ & $0.5 \pm 0.2$ & 0.72 & 0.12 \\
\cline { 1 - 2 }$(5: 1)$ & $0.6 \pm 0.5$ & & \\
\hline
\end{tabular}

Left uterine artery resistance index

\begin{tabular}{llll}
\hline$(2.5: 1)$ & $0.5 \pm 0.1$ & 0.6 & 0.31 \\
\cline { 1 - 2 }$(5: 1)$ & $0.5 \pm 0.2$ & & \\
\hline
\end{tabular}

The aim of the current study was to evaluate vascular resistance in pregnant women treated with $\mathrm{ASA}+$ omega in comparison to pregnant women treated only with ASA, since previous studies have already found increased uterine artery flow and, consequently, satisfactory blood supply in these patients. By acting as substrate for the synthesis of anti-inflammatory mediators, they positively changed thromboxane and prostaglandin E2 production, which would hypothetically contribute to longer gestational periods, higher birth weight, lower risk of preeclampsia development and to the birth of newborns small for their gestational age [22]. However, not all studies have evaluated high-risk pregnancies and many of them did not find effects beneficial enough to enable generalizing the use of these drugs by all pregnant women [27,28]. Other studies have evaluated specific groups of pregnant women such as smokers. In this case, omega-3 supplementation was associated with lower risk of spontaneous preterm birth in smokers $(\mathrm{RR}=0.56 ; 95 \% \mathrm{CI}$; 0.36-0.87) than in nonsmokers $(\mathrm{RR}=1.04$; 95\% CI; 0.84-1.29). In addition, low birth weight was less often diagnosed in babies born from smokers subjected to omega-3 supplementation $(\mathrm{RR}=0.57,95 \% \mathrm{CI} 0.36-0.90)$ than in babies born from nonsmokers ( $R R=0.93 ; 95 \% \mathrm{CI}$; 0.71-1.24) [29].

Although, in theory, omega 3 can decrease the likelihood of preeclampsia development, several studies did not show this effect. Assumingly, these differences are associated with the selected samples, with the adopted omega dose or even with the DHA: EPA ratio in the ingested compound, as well as with the time when compound supplementation was introduced [22]. Apparently, although the omega+ASA association led to higher uterine artery pulsatility and resistance indices, results in the current study were contradictory because there was not increase in the frequency of preeclampsia, in low birth weight or in any other unfavorable outcome. Actually, babies born from pregnant 
women treated with omega+ASA presented increased birthweight, although it was not statistically significant.

These apparently contradictory findings may be associated with the adopted intervention, since the omega-3 drug combination comprised both EPA and DHA. Some studies have shown that DHA prevents placental apoptosis; therefore, it would reduce preeclampsia, since DHA alone is believed to be more effective as antioxidant and anti-inflammatory medication than its association with EPA [30,31]. The supplementation of pregnant women with omega 3 appears to be associated with increased placental DHA concentration, but not with increased placental EPA. This finding suggests that placental EPA levels can be regulated regardless of maternal levels, a fact that leads to differences in the uptake, accumulation or transfer of these fatty acids to the placenta [32].

Thus, assumingly, the herein observed differences may be associated with the concentration of fatty acids in the formulations provided to patients. Omega formulations used in the current study presented different DHA:EPA ratios-studies have shown that DHA is a better inflammation modulator than EPA [33]. Therefore, the EPA:DHA ratio (2.5:1) did not appear to be effective. Pulsatility indices were lower when the DHA/EPA ratio was 5:1, although it did not represent statistical significance. Therefore, based on the assumption that other ratios may have significant effect on the evaluated variables, our research group will keep on investigating in order to find the best ratio.

The optimal omega 3 dose is also an issue that has not yet been solved. The current study used the dose of $400 \mathrm{mg}$ of omega 3, on average. Studies have shown that the omega curve appears to be U-shaped; thus, low or high doses may weaken omega's antiinflammatory action. Therefore, selecting an optimal omega 3 remains an open question. Olafsdottir et al. [34] have evaluated the risk of pregnancy-induced hypertension (PIH) and preeclampsia in a population presenting high intake of cod liver oil rich in long-chain polyunsaturated fatty acids (LCPUFA)their best results were recorded for the intake of 100 to $900 \mathrm{mg}$ of omega 3/day. These results are consistent with the ones reported by Clausen et al. [35], who found that high PUFA intake was associated with increased risk of preeclampsia development. In addition, one cannot neglect that maternal, placental and/or fetal metabolism can present significant interindividual differences. Thus, the best dose to achieve the best result may vary, but it appears that the omega 3 dose used in the current study was adequate [34].

With respect to secondary outcomes, the comparison between ASA use in association, or not, with omega did not show difference in PE, prematurity, oligohydramnios, IUGR or hospitalization in neonatal ICU frequency-results were not statistically significant. Based on the comparison between birth weights, the weight of babies born from mother treated with Omega+ASA was higher $(3,167.5 \pm 95.4 \mathrm{~g})$ that that of babies born from mothers treated only with ASA $(3,109.0 \pm 48,094 \mathrm{~g})$, although the difference was not statistically significant $(\mathrm{p}=0.85)$ [35].
However, the current research was a pilot study; thus, it is necessary increasing the number of patients to fully assess these results. It is worth highlighting that the study did not record any complications, such as bleedings and thrombocytopenia, caused by the Omega+ASA association. These data corroborate the study by Offman et al. [36], who did not find major complications resulting from associations such as omega + aspirin and omega+warfarin.

Although some studies have shown the beneficial effects of longchain omega 3 fatty acids in reducing preeclampsia, the current study did not find these benefits and did not evaluate subgroups such as diabetic patients, smokers or pregnant women presenting risk factors for premature labor [37-39]. Assumingly, in addition to individual variations that, in our viewpoint, are harder to be evaluated, the DHA: EPA ratio in the formulation was one of the determining factors of the apparently contradictory results. The present study remains in progress; it is now based on higher omega 3 doses $(500 \mathrm{mg} /$ day $)$ and on higher DHA proportion (100\%), although without its association with EPA.

\section{CONCLUSION}

Omega 3 use in association with ASA has increased the uterine artery resistance and pulsatility indices of the investigated patients; however, it did not make any difference in primary and secondary outcomes. Assumingly, DHA/EPA ratios were associated with these differences. The present study remains in progress; it is now based on changing omega 3 concentrations and on EPA exclusion from the formulation.

\section{REFERENCES}

1. Artico LG, Madi JM, Godoy AEG, Coelho CP, Rombaldi RL, Artico GR. Alterações histopatológicas em placentas humanas relacionadas às síndromes hipertensivas. Revista Brasileira de Ginecologia e Obstetrícia. 2009;31(1): 10-16.

2. Corrêa RR, Gilio DB, Cavellani CL, Paschoini MC, Oliveira FA, Peres LC, et al. Placental morphometrical and histopathology changes in the different clinical presentations of hypertensive syndromes in pregnancy. Arch Gynecol Obstet. 2008;277(3): 201-206.

3. Granger JP, Alexander BT, Llinas MT, Bennett WA, Khalil RA. Pathophysiology of hypertension during preeclampsia linking placental ischemia with endothelial dysfunction. Hypertension. 2001;38(3): 718-722.

4. Pereira LMG, Brandão AHF, Antunes AA, Leite HV, Cabral ACV. Utilização do doppler de artérias uterinas para predição da préeclâmpsia em portadoras de fatores de risco. Rev Med Minas Gerais. 2014;24(1): 45-53.

5. Jim B, Sharma S, Kebede T, Acharya A. Hypertension in pregnancy: A comprehensive update. Cardiol Rev. 2010;18: $178-89$.

6. Myatt L, Webster RP. Is vascular biology in preeclampsia better? J Thromb Haemost. 2009;7(3): 375-384.

7. Reis ZSN, Lage EM, Teixeira PG, Porto L, Guedes LR, Oliveira ECL, et al. Pré-eclâmpsia precioce e tardia: Uma classificação mais adequada para o prognóstico materno e perinatal? Rev Bras Ginecol Obstet. 2010;32(12): 584-590.

8. Gómez O, Figueras F, Fernández S, Bennasar M, Martínez JM, Puerto B, et al. Reference ranges for uterine artery mean pulsatility 
index at 11-41 weeks of gestation. Ultrasound Obstet Gynecol. 2008; 32(2): 128-132.

9. Trivedi NA. A meta-analysis of low-dose aspirin for prevention of preeclampsia. J Postgrad Med. 2011;57(2): 91-95.

10. Ruano R, Fontes RS, Zugaib M. Prevention of preeclampsia with lowdose aspirin: A systematic review and meta-analysis of the main randomized controlled trials. Clinics (Sao Paulo). 2005;60(5): 407-414.

11. Henderson JT, Whitlock EP, O'Connor E, Senger CA, Thompson $\mathrm{JH}$, Rowland MG. Low-dose aspirin for the prevention of morbidity and mortality from preeclampsia: A systematic evidence reviewfor the U.S. Preventive Services Task Force. Ann Intern Med. 2014;160(10): 695-703.

12. Rolnik DL, Wright D, Poon L, O'Gorman N, Syngelaki A, Matallana CP, et al. Aspirin versus placebo in pregnancies at high risk for preterm preeclampsia. N Engl J Med. 2017;377: 613-622.

13. Wright D, Poon LC, Rolnik DL, Syngelaki A, Delgado JL, Vojtassakova D, et al. Aspirin for evidence-based preeclampsia prevention trial: Influence of compliance on beneficial effect of aspirin in prevention of preterm preeclampsia. Am J Obstet Gynecol. 2017;217(6): 685.e1-685.e5.

14. Poon LC, Shennan A, Hyett JA, Kapur A, Hadar E, Divakar H, et al. The international federation of gynecology and obstetrics (FIGO) initiative on pre-eclampsia: A pragmatic guide for firsttrimester screening and prevention. Int J Gynaecol Obstet. 2019;145(1): 1-33.

15. Xu TT, Zhou F, Deng CY, Huang GQ, Li JK, Wang XD. Lowdose aspirin for preventing preeclampsia and its complications: a meta-analysis. J Clin Hypertens. 2015;17(7): 567-573.

16. De Berardis G, Lucisano G, D'Ettorre A, Pellegrini F, Lepore V, Tognoni $G$, et al. Association of aspirin use with major bleeding in patients with and without diabetes. JAMA. 2012;307(21): 2286-2294.

17. Sete MRC, Figueredo CMS. Periodontite e ômega 3: O papel dos ácidos graxos no processo inflamatório. Braz J Healt Biomed Sci. 2013.

18. Bessa V. Ácidos gordos ómega-3 na gravidez. Faculdade de Ciências da Nutrição e Alimentação da Universidade do Porto. 2012.

19. Silva DRB, Junior PFM, Soares EA. A importância dos ácidos graxos poliinsaturados de cadeia longa na gestação e lactação. Rev Bras Saúde Matern Infant. 2007;7(2): 123-133.

20. Santos ES, Silva DMF, Frotal DC, Garcia YR. Uso de ácidos graxos poli-insaturados durante a gestação: Um estudo bibliográfico. REAS/EJCH. 2018;11(1): 1-10.

21. Arvizu M, Afeiche MC, Hansen S, Halldorsson TF, Olsen SF, Chavarro JE. Fat intake during pregnancy and risk of preeclampsia: A prospective cohort study in Denmark. Eur J Clin Nutr. 2019;73(7): 1040-1048.

22. Burchakov DI, Kuznetsova IV, Uspenskaya YB. Omega-3 longchain polyunsaturated fatty acids and preeclampsia: Trials say "no," but is it the final word? Nutrients. 2017.

23. Kemse N, Sundrani D, Kale A, Joshi S. Maternal micronutrients, omega-3 fatty acids and gene expression of angiogenic and inflammatory markers in pregnancy induced hypertension rats. Arch Med Res. 2017;48(5): 414-422.

24. FEBRASGO. Ficha clínica de pré-natal. 2019.

25. ACOG Statement on USPSTF final recommendations on screening for preeclampsia, 2017.
26. NICE Guideline. Hypertension in pregnancy. 2019.

27. Acid supplementation of women with low-risk pregnancies on pregnancy outcomes and growth measures at birth: A metaanalysis of randomized controlled trials. Am J Clin Nutr. 2006;83(6): 1337-1344.

28. Saccone G, Saccone I, Berghella V. Omega-3 long-chain polyunsaturated fatty acids and fish oil supplementation during pregnancy: Which evidence? J Matern Fetal Neonatal Med. 2016;29(15): 2389-2397.

29. Kuper SG, Abramovici AR, Jauk VC, Harper LM, Biggio JR, Tita AT. The effect of omega-3 supplementation on pregnancy outcomes by smoking status. Am J Obstet Gynecol. 2017 217(4): 476.e1-476.e6.

30. Wietrak E, Kaminski K, Leszczyńska-Gorzelak B, Oleszczuk J. Effect of docosahexaenoic acid on apoptosis and proliferation in the placenta:Preliminary Report. Biomed Res Int. 2015; pp: 1-15.

31. Zhang YP, Brown RE, Zhang PC, Zhao YT, Ju XH, Song C. Send to DHA, EPAand their combination at various ratios differently modulated A 225-35-induced neurotoxicity in SH-SY5Y cells. Prostaglandins Leukot Essent Fatty Acids. 2018;136: 85-94.

32. Keelan JA, Mas E, D'Vaz N, Dunstan JA, Li S, Barden AE, et al. Effects of maternal n-3 fatty acid supplementation on placental cytokines, pro-resolving lipid mediators and their precursors. Reproduction. 2015;149(2): 171-178.

33. Allaire J, Couture P, Leclerc M, Charest A, Marin J, Lépine MC, et al. A randomized, crossover, head-to-head comparison of eicosapentaenoic acid and docosahexaenoic acid supplementation to reduce inflammation markers in men and women: The Comparing EPA to DHA (ComparED) Study. Am J Clin Nutr. 2016; 104:280-287.

34. Olafsdottir A, Skuladottir G, Thorsdottir I, Hauksson A, Thorgeirsdottir H, Steingrimsdottir L. Relationship between high consumption of marine fatty acids in early pregnancy and hypertensive disorders in pregnancy. $\mathrm{Br}$. J. Obstet. Gynaecol. 2006;113(3): 301-309.

35. Clausen T, Slott M, Solvoll K, Drevon CA, Vollset SE, Henriksen T. High intake of energy, sucrose, and polyunsaturated fatty acids is associated with increased risk of preeclampsia. Am J Obstet Gynecol. 2001;185(2): 451-458.

36. Offman E, Davidson M, Nilsson C. No effect of omega-3 carboxylic acids on pharmacokinetics/pharmacodynamics of warfarin or on platelet function when co-administered with acetylsalicylic acid: Results of two Phases I studies in healthy volunteers. Am J Cardiovasc Drugs.2017;17(3): 251-260.

37. Ostadrahimi A, Mohammad-Alizadeh S, Mirghafourvand M, Farshbaf-Khalili S, Jafarilar-Agdam N, Farshbaf-Khalili A. The effect of fish oil supplementation on maternal and neonatal outcomes: A triple-blind, randomized controlled trial. J Perinat Med. 2017;45(9): 1069-1077.

38. Leghi GE, Muhlhausler BS. The effect of n-3 LCPUFA supplementation on oxidative stress and inflammation in the placenta and maternal plasma during pregnancy. Prostaglandins Leukot Essent Fat Acids. 2016;113: 33-39.

39. Lim WY, Chong M, Calder PC, Kwek K, Chong YS, Gluckman $\mathrm{PD}$, et al. Relations of plasma polyunsaturated Fatty acids with blood pressures during the 26th and 28th week of gestation in women of Chinese, Malay, and Indianethnicity. Medicine (Baltimore). 2015;94(9): 571. 